\title{
CONFIGURAÇ̃̃ES TEÓRICAS DA PRODUC̣ÃO DOUTORAL BRASILEIRA SOBRE RECURSOS DIDÁTICOS NO ENSINO DE BIOLOGIA (1972-2014)
}

\author{
LILLIANE MIRANDA FREITAS ${ }^{*}$ \\ https://orcid.org/0000.0003-2935-1309 \\ EVANDRO GHEDIN" ** \\ https://orcid.org/000.0002-2844-6122
}

RESUMO: Nesta pesquisa analisamos os fundamentos teóricos da produção doutoral brasileira sobre Recursos Didáticos no Ensino de Biologia (EB) (1972-2014). Para isso, realizamos: i) sistematização de 876 dissertações e teses em EB (2005-2014); ii) análise hermenêutica de 24 teses sobre o foco temático Recursos Didáticos em EB (1972 a 2014), para análise do quadro teórico. Foram identificados fundamentos teóricos relacionados às abordagens Construtivistas, Perspectivas Críticas, Teorias da Linguagem e Teoria da Transposição Didática. Consideramos que as pesquisas sobre Recursos Didáticos em EB no Brasil estão fundamentadas em um compêndio teórico particular, que não mais se ancora apenas em referências gerais da Educação, Psicologia ou Filosofia, mas leva em conta a realidade educacional brasileira e as especificidades dos conteúdos biológicos e científicos.

Palavras-chave: Ensino de Biologia; Recursos Didáticos; Pressupostos teóricos; Estado da Arte.

\section{CONFIGURACIONES TEÓRICAS DE LA PRODUCCIÓN DOCTORAL BRASILEÑA SOBRE RECURSOS DIDÁCTICOS EN LA ENSEÑANZA DE BIOLOGÍA (1972-2014)}

RESUMEN: En esta investigación analizamos los fundamentos teóricos de la producción doctoral brasileña sobre Recursos Didácticos en la Enseñanza de Biología (EB) (1972-2014). Para ello, realizamos: i) sistematización de 876 disertaciones y tesis en EB (2005-2014); ii) análisis hermenéutico de 24 tesis sobre el foco temático Recursos Didácticos en EB (1972 a 2014), para análisis del cuadro teórico. Se identificaron fundamentos teóricos

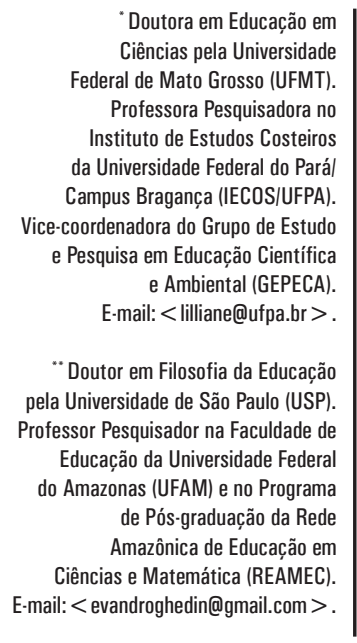

·Doutora em Educação em Ciencias pela Universidade Professora Pesquisadora no Instituto de Estudos Costeiros da Universidade Federal do Pará/ Campus Bragança (IECOS/UFPA) ice-coordenadora do Grupo de Estudo Ambiental (GEPECA). -mail: < lilliane@ufpa.br>

“* Doutor em Filosofia da Educação
pela Universidade de São Paulo (USP).
Professor Pesquisador na Faculdade de
Educação da Universidade Federal
do Amazonas (UFAM) e no Programa
de Pós-graduação da Rede
Amazônica de Educação em
Ciências e Matemática (REAMEC).
E-mail: < evandroghedin@gmail.com>.

' Universidade Federal do Pará, Instituto de Estudos Costeiros, Bragança, PA - Brasil.

" Universidade Federal do Amazonas, Faculdade de Educação, Manaus, , AM - Brasil. 
relacionados con los enfoques Constructivistas, Perspectivas Críticas, Teorías del Lenguaje y Teoría de la Transposición Didáctica. Consideramos que las investigaciones sobre Recursos Didácticos en EB en Brasil se fundamentan en un compendio teórico particular, que ya no se basa sólo en referencias generales de la Educación, Psicología o Filosofía, sino que tiene en cuenta la realidad educativa brasileña y las especificidades de los contenidos biológicos y científicos.

Palabras clave: Enseñanza de Biología; Recursos Didácticos; Presupuestos teóricos; Estado del arte.

\section{THEORETICAL CONFIGURATIONS OF BRAZILIAN DOCTORAL PRODUCTION ON TEACHING RESOURCES IN THE TEACHING OF BIOLOGY (1972-2014)}

ABSTRACT: In this research we analyze the theoretical foundations of Brazilian doctoral production on Didactic Resources in Teaching of Biology (TB) (1972-2014). For this, we performed: i) systematization of 876 dissertations and theses in TB (2005-2014); Ii) hermeneutical analysis of 24 theses on the thematic focus Didactic Resources in TB (1972 to 2014), to analyze the theoretical framework. Theoretical foundations related to Constructivist approaches, Critical Perspectives, Language Theories and Didactic Transposition Theory were identified. We consider that the research on Didactic Resources in EB in Brazil is based on a particular theoretical compendium, which is no longer anchored only in general references of Education, Psychology or Philosophy, but takes into account the Brazilian educational reality and the specificities of biological and scientific content.

Keywords: Teaching of Biology; Didactic Resources; Theoretical assumptions; State of the art. 


\section{INTRODUÇÃO}

A área de pesquisa em Ensino de Ciências (EC) completa 45 anos de intensa produção acadêmica nos cursos de pós-graduação sediados em diferentes Instituições de Ensino Superior por todo território nacional. A consolidação desta área tornou a produção mais constante e consistente, devido à solidificação de linhas e grupos de pesquisa, projetos de pesquisa financiados, promoção de eventos e organização de revistas no interior de programas de mestrado e doutorado, congregando as subáreas de Biologia, Física, Ciências, Química, Geologia, Saúde e Educação Ambiental.

Os primórdios da construção da área de EC foram marcados por duas características articuladas: a frequente importação de aportes teóricos de áreas distintas, até mesmo devido à natureza interdisciplinar da área; e a ênfase na aplicabilidade da pesquisa. Em sua origem, para que a EC se firmasse como área científica era necessário estar fortemente articulada com campos disciplinares já consolidados, como a Psicologia e a Educação, uma vez que era ausente uma teoria geral própria relativa ao ensino, à aprendizagem e a formação em EC (CACHAPUZ et al., 2004).

A evidência no caráter prático ou instrumental dado às pesquisas nos primórdios da área estava relacionada, de certa maneira, a aplicações de teorias e modelos das Ciências Humanas, particularmente, da Psicologia. Nardi (2005) verificou na fala de alguns dos pesquisadores pioneiros da área que as primeiras investigações em EC tinham como principal objetivo a geração de condições e processos aplicáveis no ensino de ciências no país, acreditavam que por se tratar de pesquisa aplicada, não seria uma preocupação primeira desenvolver teorias relativas ao ensino de ciências.

Mesmo nos primórdios da área, Villani (1984) já fazia um contraponto a essa ideia ao considerar que a simples preocupação com a resolução de um problema prático, sem aprofundá-lo no contexto das características do EC, e sem a preocupação com a sua eventual reprodutibilidade e com a análise e a avaliação crítica da comunidade científica, não caracteriza uma pesquisa fundamental. Em outras palavras, qualquer tipo de atividade feita com o único intuito de melhorar a prática em sala de aula ou aumentar a motivação dos alunos, sem nenhum tipo de registro sistemático ou pelo menos de reflexão que esclareça de alguma forma, para a comunidade científica, a contribuição oferecida, não é pesquisa fundamental.

Ao apontar essas questões, não estamos considerando que a importação de referenciais e a pesquisa aplicada sejam um mal em si mesmo. No entanto, consideramos que a ênfase nesses aspectos pode causar dificuldades para a evolução da área. Pois, o não tratamento ou a fragilidade na abordagem de questões teóricas pode impedir a construção de um quadro teórico próprio e de referência consistente, na medida em que pode induzir o aparecimento de referenciais teóricos pouco coerentes e/ou pontuais, o que traz sérias implicações à construção da identidade epistêmica da área. Pietrocola-Oliveira (1994), menciona que as consequências da fragilidade teórica são nefastas, uma vez que possivelmente, levam à troca constante de abordagens, à superficialidade no estudo dos problemas, à mistura de concepções antagônicas, que acabam sendo agrupadas sob um mesmo rótulo, etc.

Nossa preocupação teórica encontra eco nas considerações de vários outros autores que têm refletido quanto essas questões, ao longo da constituição da área de EC. Autores como Almeida (1994), Pietrocola-Oliveira (1994), Villani 
(1994), Moreira (2004), Lopes et al. (2005) discutiram sobre a pequena ênfase dada nas pesquisas na elaboração de uma estrutura teórica coerente e própria de EC e a necessidade de trabalhar mais em prol da consolidação epistêmica para dar-lhe mais identidade. Isso geraria maior clareza sobre o que se produz e os propósitos da área, tanto para comunidade interna quanto externa, ajudando na construção de uma imagem global mais equilibrada.

Poucos trabalhos têm se dedicado a compreender a constituição teórica da área de EC, o que nos indica que não houve muitos avanços nesse sentido. Essa ausência pode ser inclusive percebida em trabalhos do tipo estado da arte, pois a quase totalidade destes trabalhos não analisa o descritor referenciais teóricos, voltando-se muito mais para os focos temáticos, sujeitos investigados, instituições, etc. Segundo Fernandes e Megid-Neto (2007), que realizaram uma metapesquisa sobre as pesquisas do tipo estado da arte, dos 18 trabalhos analisados no período de 1996 a 2007, somente três (LEMGRUBER, 1999; DELIZOICOV, 2004; GRECA et al. 2002) dedicaram-se a investigar questões teóricas na produção da área de EC.

Na subárea de Ensino de Biologia (EB), quatro trabalhos inventariaram e analisaram a produção acadêmica em EB, que são os de Slongo (2004), Teixeira (2008; 2015) e Freitas (2016). Slongo (2004) analisou 130 textos de teses e dissertações (T\&D) em EB no período de 1972-2000, a partir das quais identificou três períodos de desenvolvimento da pesquisa em EB, caracterizados por transformações ocorridas em vários pressupostos que fundamentam as investigações realizadas ao longo das três décadas consideradas. Teixeira (2008) analisou 351 documentos de T\&D em EB no período entre 1972-2004 com objetivo de explicitar dados sobre a base institucional que sustenta esse campo investigativo e as tendências da produção sobre o EB no Brasil.

Teixeira (2015) analisou um conjunto de 163 teses no período 1972-2011 e apontou características e tendências dessa produção. Ele afirma que desse total, apenas seis são classificadas como ensaios ou trabalhos de natureza teórica, e devido a essa escassez argumenta que essa modalidade de estudos acadêmicos precisa ser explorada de forma mais intensa. Freitas (2016) analisou um total de 876 T\&D em EB no período de 2005 a 2014, com base nos descritores ano, instituição, foco temático, conteúdos biológicos e nível de ensino, para compreender a partir das teses brasileiras sobre Recursos Didáticos de que forma a área de EB em se constituído em torno de referenciais teóricos particulares, suas condições históricas de produção, surgimento e influências, e como estes contribuíram para sua evolução epistemológica.

Demonstrada a carência de trabalhos no sentido de analisar a natureza teórica da área de EC, e em particular da subárea de EB, e as implicações que isto gera à sua constituição e evolução enquanto campo de pesquisa, partimos das seguintes questões de investigação: Que configurações teóricas emergem da pesquisa sobre Recursos Didáticos no Ensino de Biologia, a partir das pesquisas brasileiras em nível doutoral? Como elas projetam teoricamente a área de Ensino de Biologia no Brasil?

Nosso objetivo com as teses sobre Recursos Didáticos (RD) foi mapear os pressupostos teóricos, identificando autores e referências que fundamentam as pesquisas sobre RD na área de EB nos últimos anos. Teixeira (2008) afirmava que essa era uma importante lacuna a ser preenchida, e no qual nos lançamos, o desvelar de detalhes da produção em EB realizada através de recortes específicos 
sobre determinados focos temáticos, que em seu e em outros trabalhos, foram apresentados em uma perspectiva mais abrangente.

Portanto, esta pesquisa relata um estudo teórico que se desenvolveu como uma metapesquisa, possibilitando-nos a análise hermenêutica dos fundamentos teóricos em obras em nível doutoral na área de EB. Consideramos que esta é uma importante contribuição para a consolidação da área como campo de produção de conhecimento e, especialmente, virá contribuir com a construção epistemológica do campo de EB e a formação inicial de pesquisadores e professores desta área. Além disso, estaremos contribuindo para o processo de divulgação da própria produção acadêmica em EB e subsidiando estudos mais específicos ao apontar questões, lacunas, características e aspectos importantes da subárea de Ensino de Biologia.

\section{PROCEDIMENTOS METODOLÓGICOS}

A pesquisa foi realizada em duas etapas. A primeira etapa consistiu numa revisão em extensão da produção acadêmica no formato de dissertações e teses em EB defendidas no período de 2005 a 2014. Buscamos atualizar o inventário em período posterior ao investigado por Teixeira (2008) de 1972 a 2004. O período final definido para seleção das obras, de 2014, foi devido ao fechamento do projeto de pesquisa de doutoramento do qual resulta este trabalho.

$\mathrm{Na}$ primeira etapa foram encontrados 876 trabalhos acadêmicos em EB, sendo 171 teses e 705 dissertações de mestrado. A partir da seleção e leitura dos resumos, as informações das 876 pesquisas foram organizadas com base nos seguintes descritores: i) ano; ii) instituição; iii) foco temático; iv) conteúdos biológicos; e v) nível de ensino pesquisado. Os resultados dessa sistematização podem ser consultados em Freitas (2016). Essa visão panorâmica foi necessária para a compreensão dos pressupostos teóricos e os contextos de produção subjacentes nas teses sobre RD em EB e para justificarmos a decisão pelo recorte que procedemos no montante dessa produção com objetivo de garantir o refinamento das análises.

Conscientes da possibilidade dos riscos que os recortes impõem à pesquisa e, ao mesmo tempo, que só o isolamento de partes da realidade possibilita a sua investigação; em função da grande quantidade de documentos, decidimos realizar dois recortes no universo amostral de 876 pesquisas sistematizadas na primeira etapa da pesquisa. O primeiro recorte teve como referência o nível acadêmico, em que foram selecionadas as teses de doutorado para constituir o corpus de análise (171 teses). Acreditamos que as pesquisas em nível doutoral possuem um rigor teórico-metodológico mais elevado em função do tempo para produzir o texto da tese ser maior e, pelo grau de maturidade do próprio pesquisador, o que pode resultar na produção de pesquisas mais coerentes em termos teóricometodológicos e com questões e resultados com maior pertinência e relevância para o campo de pesquisa em EB.

Além desses aspectos, grande parte das teses é utilizada como referenciais teóricos que fundamentam outras T\&D posteriores. Segundo Cunha (1991), as referências bibliográficas nacionais na área de educação, no formato de livros e artigos em revistas, são produtos das T\&D defendidas nos programas de pósgraduação. De forma que, ao lançar olhar para as teses em EB, entraremos em 
contato com as principais referências da área, tanto as que são utilizadas nelas, quanto estaremos diante de possíveis referências que sustentarão trabalhos futuros.

Sobre o montante de 171 teses em EB encontrado entre 2005 e 2014, procedemos com um segundo recorte, feito pelo descritor "foco temático" mais significativo quantitativamente identificado na primeira etapa da pesquisa. Escolhemos este descritor "foco temático" por considerá-lo o mais importante entre os demais descritores (ano, instituição, conteúdos biológicos e nível de ensino), uma vez que revela tendências e perspectivas da produção acadêmica, tanto em relação aos objetivos e questões de investigação que privilegiam, quanto aos referenciais teóricos que adotam, contextos históricos que revelam, por isso, esse descritor demanda um estudo mais aprofundado.

$\mathrm{Na}$ sistematização realizada na primeira etapa da pesquisa verificamos que os principais focos temáticos abordados nas pesquisas em EB foram: Recursos Didáticos (22\%); Conteúdo-Método (20\%); Características do Professor (13\%); Características do aluno (11\%); Currículos e Programas (11\%) e Formação de Professores (10\%) (FREITAS, 2016). Esses seis focos temáticos aglutinam 87\% das pesquisas e ocorreram em todos os anos do período em questão (Tabela 1).

Tabela 1. Focos temáticos das 876 teses e dissertações em Ensino de Biologia analisadas no período de 2005 a 2014. 0 quantitativo de trabalhos nos focos temáticos (944) excede 0 número real de trabalhos (876), pois muitas pesquisas possuem um foco principal e outro(s) secundário(s).

\begin{tabular}{|c|c|c|c|c|c|c|c|c|c|c|c|c|}
\hline \multirow{2}{*}{ Focos temáticos } & \multicolumn{10}{|c|}{ Ano (2005-2014) } & \multirow{2}{*}{ Total } & \multirow{2}{*}{$\%$} \\
\hline & 05 & 06 & 07 & 08 & 09 & 10 & 11 & 12 & 13 & 14 & & \\
\hline Recursos Didáticos & 13 & 15 & 8 & 26 & 17 & 37 & 33 & 21 & 20 & 18 & 208 & 22 \\
\hline $\begin{array}{l}\text { Conteúdo- } \\
\text { Método }\end{array}$ & 13 & 6 & 9 & 20 & 31 & 19 & 16 & 13 & 29 & 29 & 185 & 20 \\
\hline $\begin{array}{l}\text { Características } \\
\text { do Professor }\end{array}$ & 4 & 6 & 11 & 12 & 19 & 14 & 17 & 9 & 13 & 21 & 126 & 13 \\
\hline $\begin{array}{l}\text { Características } \\
\text { do Aluno }\end{array}$ & 6 & 12 & 7 & 11 & 15 & 17 & 7 & 17 & 7 & 10 & 109 & 11 \\
\hline $\begin{array}{l}\text { Currículos e } \\
\text { Programas }\end{array}$ & 5 & 8 & 7 & 8 & 7 & 16 & 17 & 8 & 10 & 15 & 101 & 11 \\
\hline $\begin{array}{l}\text { Formação de } \\
\text { Professores }\end{array}$ & 6 & 11 & 8 & 7 & 4 & 10 & 9 & 9 & 10 & 21 & 95 & 10 \\
\hline $\begin{array}{l}\text { História e Filosofia } \\
\text { da Ciência }\end{array}$ & 4 & 4 & 2 & 4 & 2 & 6 & 3 & 4 & 10 & 7 & 46 & 5 \\
\hline $\begin{array}{l}\text { Educação } \\
\text { não-Formal }\end{array}$ & 1 & 5 & 4 & 3 & 1 & 2 & 5 & 4 & 3 & 4 & 32 & 3 \\
\hline $\begin{array}{l}\text { Formação de } \\
\text { Conceitos }\end{array}$ & 2 & 2 & 5 & 3 & 2 & 2 & 2 & 3 & 3 & 1 & 25 & 3 \\
\hline Outros & 0 & 1 & 0 & 1 & 0 & 1 & 4 & 4 & 2 & 0 & 13 & 1 \\
\hline $\begin{array}{l}\text { Organização } \\
\text { da Escola }\end{array}$ & 0 & 0 & 0 & 0 & 1 & 1 & 0 & 0 & 0 & 2 & 4 & 1 \\
\hline Total & 54 & 70 & 61 & 95 & 99 & 125 & 113 & 92 & 107 & 128 & 944 & 100 \\
\hline
\end{tabular}


Verificamos que o foco temático Recursos Didáticos, com um conjunto de 208 trabalhos, sendo 24 teses e 184 dissertações, foi o que mais aglutinou trabalhos e por isso representou de forma mais significativa, em termos quantitativos, o interesse dos pesquisadores por este tema na área de EB. Além dessa razão quantitativa, nosso recorte pela análise das teses sobre RD ocorreu também por um critério qualitativo, uma vez que os trabalhos agrupados no foco temático RD lidam diretamente com o ensino dos conteúdos das Ciências Biológicas, quando estas propõem e/ou avaliam a aplicação de determinados materiais didáticos no ensino de algum conteúdo específico da Biologia.

Além das 24 teses sobre RD encontradas no período de 2005 a 2014, incluímos nesse conjunto mais cinco teses sobre RD defendidas entre 1972 e 2004, identificadas por Teixeira (2008), para que pudéssemos ter uma visão geral dessa produção desde a fundação da área. Dessa maneira, nosso conjunto analítico compreende todas as 29 teses publicadas em EB sobre RD desde 1972 até 2014. Dada a seleção abalizada nos critérios de recorte definidos acima, o passo seguinte foi a busca das 29 teses na íntegra para procedermos com a leitura e análise das teses em sua totalidade. Das 29 teses sobre RD apenas cinco não estavam disponíveis, totalizando 24 documentos disponíveis para consulta, sobre os quais desenvolvemos as análises.

Ao analisarmos um conjunto de teses em EB, procedemos com uma pesquisa do tipo bibliográfica, que é uma modalidade de estudo e análise de documentos de domínio científico (SÁ-SILVA et al., 2009). Neste caso, a hermenêutica é apontada como um instrumento metodológico de grande potencial, uma vez que ela se propõe a compreensão de obras teóricas ou poéticas, isto é, configura-se como um instrumento para análise e compreensão de discursos filosóficos, políticos, pedagógicos (GHEDIN; FRANCO, 2011; SILVA, 2011). Desta feita, adotamos como instrumento metodológico a hermenêutica crítica proposta por Paul Ricoeur, para quem a hermenêutica "é a teoria das operações da compreensão em sua relação com a interpretação dos textos; na efetuação do discurso como texto" (RICOEUR, 1990, p. 17). Portanto, nossa perspectiva é de uma ciência compreensiva, que busca a compreensão de sentidos de nosso objeto de estudo que são as teses sobre RD em EB.

Vale ressaltar que analisamos os discursos que emergiram das obras, e o discurso, na perspectiva de Ricoeur (1990), ocorre como evento, como fenômeno temporal da troca, do diálogo, refere-se a um mundo que pretende descrever, representar e, ao mesmo tempo, está carregado da própria realidade que o gera. $\mathrm{O}$ discurso se inscreve na escrita, é efetuado na obra estruturada, neste caso nas teses de EB. O texto abre um mundo, o mundo da obra, constituído pela tríade discursoobra-escrita, nosso objeto de análise. Portanto, não estarão em xeque as intenções dos autores ao escreverem suas teses, pois o texto fala por si, ele é autônomo (RICOEUR, 1990). O que significa dizer que o texto se abre a uma sequência ilimitada de leituras, de interpretações, situadas em contextos socioculturais de produção diferentes, que não coincidem mais com aquilo que o autor queria dizer. Desta feita, nossa análise hermenêutica incide no potencial de sentido dos textos, buscando interpretar o mundo que ele mostra e propõe. 


\section{RESULTADOS E DISCUSSÃO}

Faremos inicialmente uma apresentação do contexto geral das teses, situando as problemáticas de investigação que nortearam essas obras. Num segundo movimento, partiremos do contexto geral das pesquisas para a hermenêutica da estrutura teórica que as sustentam, na tentativa de interpretar os sentidos dos discursos filosóficos, políticos e pedagógicos que emergem dos textos de pesquisa doutoral através da análise das teorias que lhes são estruturantes e como elas projetam teoricamente a área de EB no Brasil.

\section{CONTEXTO GERAL DAS TESES SOBRE RECURSOS DIDÁTICOS EM ENSINO DE BIOLOGIA}

O conjunto de 29 teses com o foco temático RD em EB corresponde a $12,3 \%$ do total de teses defendidas (234) no período de 1972 a 2014, e corresponde a $11,7 \%$ do total de trabalhos (246) sobre RD no mesmo período. Slongo (2004) identificou seis trabalhos, incluindo T\&D sobre RD entre 1972 e 2000. Teixeira (2008) encontrou 74 trabalhos sobre RD de 1972 a 2006, sendo quatro teses.

Verificamos que as investigações sobre RD ganharam força a partir dos anos 2000 (Tabela 2), que relacionamos ao crescimento institucional da própria área. Consideramos que o incremento das dissertações de mestrado profissional por estarem estritamente relacionadas com a prática educacional, também reflete o crescimento deste foco temático. Nesta modalidade de mestrado, regulamentados pela CAPES em 1998 (CAPES, 1998), é necessário para obter a titulação, além da dissertação, ser apresentado um produto educacional, que geralmente é um recurso didático, como, por exemplo, um software, uma cartilha, um guia, um jogo, um kit, etc.

Tabela 2. Distribuição de teses e dissertações, com destaque para as teses sobre Recursos Didáticos publicadas desde 1972 a 2014.

\begin{tabular}{l|c|c|c|c|c|c}
\hline Período & $\mathbf{7 2 - 8 0}$ & $\mathbf{8 1 - 9 0}$ & $\mathbf{9 1 - 0 0}$ & $\mathbf{0 1 - 1 0}$ & $\mathbf{1 1 - 1 4}$ & Total \\
\hline Teses em Ensino de Biologia & 3 & 3 & 28 & 101 & 99 & 234 \\
\hline Teses sobre Recursos Didáticos & - & 1 & 2 & 16 & 10 & 29 \\
\hline
\end{tabular}

A produção das 29 teses com este enfoque entre 1972 e 2014 ocorreu em dez Instituições de Ensino Superior (IES) brasileiras, todas localizadas no sul e sudeste: USP (6), FIOCRUZ (5), UNICAMP (5), UNESP (3), UFRJ (3), PUC-RS (1), UFF (1), UFMG (1), UFRGS (1), UFSC (1), UNICSUL (1) e UNIJUÍ (1). As instituições que mais se destacaram foram a USP, a FIOCRUZ e a UNICAMP, somente elas abarcam 55\% da produção sobre RD. No Quadro 1 estão classificadas, em ordem crescente de data de publicação, as 29 teses que abordaram o tema RD em EB. 
Quadro 1. Teses sobre Recursos Didáticos em Ensino de Biologia (1972 a 2014).

\begin{tabular}{|c|c|c|c|c|c|}
\hline Doc. & Ano & Autor & Título da Tese & Orientador & IES \\
\hline 1 & 1989 & Roitman, Riva & $\begin{array}{l}\text { Adoção e implementação de } \\
\text { um programa inovador em } \\
\text { escola da rede pública do } \\
\text { estado do Rio de Janeiro: uma } \\
\text { experiência e muitas lições }\end{array}$ & Nélio Parra & USP \\
\hline 2 & 1992 & $\begin{array}{c}\text { Fracalanza, } \\
\text { Dorotéa Cuevas }\end{array}$ & $\begin{array}{l}\text { Crise ambiental e ensino de } \\
\text { ecologia: o conflito na relação } \\
\text { homem-mundo natural }\end{array}$ & $\begin{array}{l}\text { Sérgio } \\
\text { Lorenzato }\end{array}$ & UNICAMP \\
\hline 3 & 1998 & $\begin{array}{l}\text { Volpe, Roberta } \\
\text { Mazzariol }\end{array}$ & $\begin{array}{l}\text { Desenvolvimento, validação e } \\
\text { avaliação da estrutura do HGEN } \\
\text { - um software integrado ao } \\
\text { processo ensino-aprendizagem } \\
\text { de Genética Médica }\end{array}$ & Denise Norato & UNICAMP \\
\hline 4 & 2002 & $\begin{array}{l}\text { Freitas, Deisi } \\
\text { Sangoi }\end{array}$ & $\begin{array}{l}\text { Imagens visuais nos livros } \\
\text { didáticos de Biologia do Ensino } \\
\text { Médio: o caso do DNA }\end{array}$ & $\begin{array}{l}\text { Cristina } \\
\text { Bruzzo }\end{array}$ & UNICAMP \\
\hline 5 & 2003 & $\begin{array}{l}\text { Braga, Selma } \\
\text { Ambrosina de } \\
\text { Moura }\end{array}$ & $\begin{array}{l}0 \text { texto de Biologia do livro } \\
\text { didático de Ciências }\end{array}$ & $\begin{array}{l}\text { Eduardo } \\
\text { Mortimer; } \\
\text { Antônio } \\
\text { Batista }\end{array}$ & UFMG \\
\hline 6 & 2005 & $\begin{array}{l}\text { Fernandes, } \\
\text { Hylio Laganá }\end{array}$ & $\begin{array}{l}\text { A fotografia como mediadora } \\
\text { subversiva na produção do } \\
\text { conhecimento }\end{array}$ & $\begin{array}{l}\text { Mariley } \\
\text { Gouveia }\end{array}$ & UNICAMP \\
\hline 7 & 2005 & $\begin{array}{l}\text { Motokane, } \\
\text { Marcelo Tadeu. }\end{array}$ & $\begin{array}{l}\text { Educação e Biodiversidade: } \\
\text { elementos do processo } \\
\text { de produção de materiais } \\
\text { pedagógicos }\end{array}$ & Silvia Trivelato & USP \\
\hline 8 & 2006 & $\begin{array}{l}\text { Oliveira, } \\
\text { Jeferson } \\
\text { Botelho }\end{array}$ & $\begin{array}{l}\text { O Tempo Geológico no Ensino } \\
\text { Fundamental e Médio: os } \\
\text { estudantes e os livros didáticos. }\end{array}$ & Nélio Bizzo & USP \\
\hline 9 & 2006 & $\begin{array}{l}\text { Silva, Marcelo } \\
\text { Alves da }\end{array}$ & $\begin{array}{l}\text { Sinalização celular: uma nova } \\
\text { abordagem para ciências } \\
\text { biológicas. }\end{array}$ & $\begin{array}{l}\text { Maria } \\
\text { Aparecida } \\
\text { Visconti }\end{array}$ & USP \\
\hline 10 & 2007 & $\begin{array}{l}\text { Cardona, Tania } \\
\text { da Silveira }\end{array}$ & $\begin{array}{l}\text { Inovação no ensino de biologia } \\
\text { celular: desenvolvimento } \\
\text { e avaliação de estratégias } \\
\text { educativas. }\end{array}$ & $\begin{array}{l}\text { Andrea } \\
\text { Henriques } \\
\text { Pons }\end{array}$ & FIOCRUZ \\
\hline 11 & 2008 & $\begin{array}{l}\text { Gomes, Maria } \\
\text { Margarida P. } \\
\quad \text { Lima }\end{array}$ & $\begin{array}{l}\text { Conhecimentos ecológicos em } \\
\text { livros didáticos de Ciências: } \\
\text { aspectos sócio-históricos de } \\
\text { sua constituição }\end{array}$ & $\begin{array}{l}\text { Sandra Lúcia } \\
\text { Escovedo } \\
\text { Selles }\end{array}$ & UFF \\
\hline
\end{tabular}




\begin{tabular}{|c|c|c|c|c|c|}
\hline 12 & 2008 & $\begin{array}{l}\text { Nascimento, } \\
\text { Tatiana Galieta }\end{array}$ & $\begin{array}{l}\text { Leituras de divulgação } \\
\text { científica na formação inicial de } \\
\text { professores de Ciências. }\end{array}$ & $\begin{array}{l}\text { Suzani } \\
\text { Cassiani de } \\
\text { Souza }\end{array}$ & UFSC \\
\hline 13 & 2008 & $\begin{array}{l}\text { Abreu-Fialho, } \\
\text { Ana Paula. }\end{array}$ & $\begin{array}{l}\text { Design instrucional e ensino e } \\
\text { aprendizagem de Bioquímica à } \\
\text { distância. }\end{array}$ & $\begin{array}{c}\text { Cristine } \\
\text { Barreto; } \\
\text { Andrea Poian }\end{array}$ & UFRJ \\
\hline 14 & 2008 & $\begin{array}{c}\text { Gianotto, } \\
\text { Dulcinéia Ester } \\
\text { Pagani }\end{array}$ & $\begin{array}{l}\text { Formação inicial de } \\
\text { professores de biologia e o } \\
\text { uso de computadores: análise } \\
\text { de uma proposta de prática } \\
\text { colaborativa. }\end{array}$ & $\begin{array}{c}\text { Renato } \\
\text { Eugenio Diniz }\end{array}$ & UNESP \\
\hline 15 & 2009 & $\begin{array}{c}\text { Freire, } \\
\text { Alexandre de Sá }\end{array}$ & $\begin{array}{l}\text { O Jogo do Genoma: um estudo } \\
\text { sobre o ensino de genética no } \\
\text { Ensino Médio. }\end{array}$ & $\begin{array}{l}\text { Milton Ozório } \\
\text { Moraes }\end{array}$ & FIOCRUZ \\
\hline 16 & 2009 & $\begin{array}{l}\text { Siqueira, Ana } \\
\text { Paula Legey }\end{array}$ & $\begin{array}{l}\text { Saberes da área de Biologia } \\
\text { celular na mídia impressa e na } \\
\text { Educação formal e avaliação } \\
\text { de jogos durante a formação } \\
\text { docente. }\end{array}$ & $\begin{array}{l}\text { Claudia Mara } \\
\text { Coutinho }\end{array}$ & FIOCRUZ \\
\hline 17 & 2010 & $\begin{array}{l}\text { Brando, } \\
\text { Fernanda da } \\
\text { Rocha }\end{array}$ & $\begin{array}{l}\text { Proposta didática para o ensino } \\
\text { médio de Biologia: as relações } \\
\text { ecológicas no cerrado }\end{array}$ & $\begin{array}{l}\text { Ana Maria } \\
\text { Caldeira }\end{array}$ & UNESP \\
\hline 18 & 2010 & $\begin{array}{l}\text { Santa-Rosa, } \\
\text { José Guilherme } \\
\text { da Silva }\end{array}$ & $\begin{array}{l}\text { Pesquisa e desenvolvimento } \\
\text { de Ambiente Virtual de } \\
\text { Aprendizagem de Histologia: } \\
\text { uma ferramenta complementar } \\
\text { de ensino-aprendizagem }\end{array}$ & $\begin{array}{l}\text { Mirian } \\
\text { Struchiner }\end{array}$ & UFRJ \\
\hline 19 & 2010 & $\begin{array}{c}\text { Silva, Aparecido } \\
\text { Rodrigues }\end{array}$ & $\begin{array}{l}\text { Desenvolvimento e avaliação de } \\
\text { modelos representativos para } \\
\text { construção de aminoácidos e } \\
\text { de estruturas de proteínas }\end{array}$ & $\begin{array}{l}\text { Leila Maria } \\
\text { Beltramini }\end{array}$ & USP \\
\hline 20 & 2011 & $\begin{array}{l}\text { Ferraro, José } \\
\text { Luis Schifino }\end{array}$ & $\begin{array}{l}\text { A biologia e o discurso sobre } \\
\text { a vida: aproximações acerca } \\
\text { do conceito de vida em livros } \\
\text { didáticos }\end{array}$ & $\begin{array}{c}\text { Marcos Villela } \\
\text { Pereira }\end{array}$ & PUC-RS \\
\hline 21 & 2011 & $\begin{array}{c}\text { Ferreira, Ana } \\
\text { Silvia Sartori B. } \\
\text { Seabra }\end{array}$ & $\begin{array}{l}\text { Elaboração e avaliação de um } \\
\text { ambiente virtual para o ensino/ } \\
\text { aprendizagem de embriologia }\end{array}$ & $\begin{array}{l}\text { Wilma } \\
\text { Kempinas }\end{array}$ & UNESP \\
\hline 22 & 2011 & $\begin{array}{l}\text { Mugnai, } \\
\text { Riccardo }\end{array}$ & $\begin{array}{l}\text { Biomonitoramento das águas: } \\
\text { estratégias para prática de } \\
\text { ensino }\end{array}$ & $\begin{array}{c}\text { Júlio Vianna } \\
\text { Barbosa }\end{array}$ & FIOCRUZ \\
\hline 23 & 2011 & $\begin{array}{c}\text { Randi, Marco } \\
\text { Antonio Ferreira }\end{array}$ & $\begin{array}{l}\text { Criação, aplicação e } \\
\text { avaliação de aulas com jogos } \\
\text { cooperativos do tipo RPG para o } \\
\text { ensino de biologia celular }\end{array}$ & $\begin{array}{l}\text { Hernandes } \\
\text { Faustino de } \\
\text { Carvalho }\end{array}$ & UNICAMP \\
\hline
\end{tabular}




\begin{tabular}{|c|c|c|c|c|c|}
\hline 24 & 2011 & $\begin{array}{l}\text { Rosa, Rosane T. } \\
\text { Nascimento }\end{array}$ & $\begin{array}{l}\text { Do gene à proteína: explorando } \\
\text { o Genbank com alunos do } \\
\text { Ensino Médio }\end{array}$ & $\begin{array}{l}\text { Elgion Lucio } \\
\text { Loreto }\end{array}$ & UFRGS \\
\hline 25 & 2012 & $\begin{array}{l}\text { Franzolin, } \\
\text { Fernanda }\end{array}$ & $\begin{array}{l}\text { Conhecimentos básicos de } \\
\text { genética segundo professores } \\
\text { e docentes e sua apresentação } \\
\text { em livros didáticos e na } \\
\text { academia: aproximações e } \\
\text { distanciamentos }\end{array}$ & Nelio Bizzo, & USP \\
\hline 26 & 2012 & $\begin{array}{l}\text { Güllich, Roque } \\
\text { Ismael da Costa }\end{array}$ & $\begin{array}{l}\text { O livro didático, o professor } \\
\text { e o ensino de ciências: um } \\
\text { processo de investigação - } \\
\text { formação - ação }\end{array}$ & Lenir Zanon & UNIJUI \\
\hline 27 & 2012 & $\begin{array}{c}\text { Correa, } \\
\text { Anderson D. }\end{array}$ & $\begin{array}{l}\text { Promoção do ensino sobre o } \\
\text { uso racional de medicamentos }\end{array}$ & Luiz Alves & FIOCRUZ \\
\hline 28 & 2014 & $\begin{array}{l}\text { Bastos, Wagner } \\
\text { Gonçalves }\end{array}$ & $\begin{array}{l}\text { A produção de vídeos } \\
\text { educativos por alunos da } \\
\text { licenciatura em biologia: um } \\
\text { estudo sobre recepção fílmica e } \\
\text { modos de leitura }\end{array}$ & $\begin{array}{l}\text { Luiz Augusto } \\
\text { Coimbra de } \\
\text { Rezende Filho }\end{array}$ & UFRJ \\
\hline 29 & 2014 & $\begin{array}{l}\text { Pinto, Beatriz } \\
\text { Pinheiro }\end{array}$ & $\begin{array}{l}\text { A utilização do recurso BLOG } \\
\text { para desenvolver estratégicas } \\
\text { pedagógicas nas aulas de } \\
\text { Biologia: uma experiência em } \\
\text { sala de aula para promover } \\
\text { uma aprendizagem significativa } \\
\text { dos impactos ambientais } \\
\text { provenientes da geração de } \\
\text { energia elétrica }\end{array}$ & $\begin{array}{l}\text { Carmen Lucia } \\
\text { Costa Amara }\end{array}$ & UNICSUL \\
\hline
\end{tabular}

* Ao longo da análise as teses são referidas pelo número a que correspondem neste Quadro, pela sigla Doc.

Com relação ao nível de ensino pesquisado nas 29 teses em RD, verificamos que o Ensino Superior é o contexto privilegiado nas investigações (12 teses), seguido pelo Ensino Médio (8 teses), Ensino Fundamental (3 teses) e EJA (1 tese). Há pesquisas que abordam dois níveis de ensino ou mais: Ensino Fundamental e Médio (2 teses), Ensino Superior e Médio (1 tese), todos os níveis (2 teses).

Quanto às problemáticas investigadas nas teses sobre RD, classificamos as teses em cinco categorias conforme Teixeira (2008), com adaptações (Tabela 3). Verificamos que há predominância de pesquisas sobre Livros Didáticos (34,5\%) e sobre as Tecnologias da Informação e Comunicação (27,6\%), seguido pelos estudos que analisaram outros tipos de recursos didáticos $(17,2 \%)$, recursos lúdicos $(13,8 \%$, ) e recursos audiovisuais e imagéticos $(6,9 \%)$. 
Tabela 3. Problemáticas investigadas nas 29 teses sobre Recursos Didáticos em Ensino de Biologia (1972-2014).

\begin{tabular}{|c|c|c|c|}
\hline Problemática & Caracterização & Documentos & $\%$ \\
\hline Livros didáticos & $\begin{array}{l}\text { Analisam os livros didáticos enquanto recurso } \\
\text { didático no ensino e aprendizagem } \\
\text { de Ciências e/ou Biologia nas salas de aula. }\end{array}$ & $\begin{array}{l}2,4,5,8 \\
11,13,20 \\
22,25,26\end{array}$ & $34,5 \%$ \\
\hline $\begin{array}{l}\text { Tecnologias da } \\
\text { Informação e } \\
\text { Comunicação } \\
\text { (TIC) }\end{array}$ & $\begin{array}{l}\text { Analisam a utilização de computadores, } \\
\text { softwares educativos, simuladores, blogs, } \\
\text { redes sociais e ambientes virtuais de } \\
\text { aprendizagem (AVA). }\end{array}$ & $\begin{array}{l}1 *, 3,9^{*} \\
14,18,21 \\
24,29\end{array}$ & $27,6 \%$ \\
\hline $\begin{array}{l}\text { Recursos } \\
\text { Lúdicos }\end{array}$ & $\begin{array}{l}\text { Examinam o emprego de jogos e histórias } \\
\text { em quadrinhos como Recursos Didáticos. }\end{array}$ & $\begin{array}{l}15,16^{*}, 23 \\
27\end{array}$ & $13,8 \%$ \\
\hline $\begin{array}{l}\text { Recursos } \\
\text { Audiovisuais e } \\
\text { Imagéticos }\end{array}$ & $\begin{array}{l}\text { Acentuam a utilização desses recursos } \\
\text { para auxiliar o processo de construção } \\
\text { de conhecimento e de mediação entre o } \\
\text { pensamento dos alunos e o conhecimento } \\
\text { científico: filmes e fotografias. }\end{array}$ & 6,28 & $6,9 \%$ \\
\hline Outros recursos & $\begin{array}{l}\text { Analisam a utilização de revistas, artigos, } \\
\text { textos diversos e a utilização de Mapas } \\
\text { conceituais. }\end{array}$ & $\begin{array}{l}7 *, 10 *, 12 \\
17,19\end{array}$ & $17,2 \%$ \\
\hline
\end{tabular}

* Os textos completos dessas obras não estavam disponíveis nas páginas eletrônicas dos respectivos programas em que foram defendidos.

No conjunto de teses que analisaram os 'Livros Didáticos' (LD), onde estão aglutinadas dez pesquisas (34,5\%), os objetos de análise nos LD são: i) como determinados conceitos/conteúdos específicos são abordados nos LD (Doc. 2, $8,11,20,25)$; ii) aspectos estruturais dos LD, como imagens e linguagem (Doc. 4 e 5); iii) contextos de produção do LD (Doc. 13 e 22); e iv) análise do LD no contexto da prática de ensino de professores de Ciências (Doc. 26).

Percebemos que há um discurso uníssono nas teses que abordam os LD, de que estes são os principais recursos utilizados pelos professores, geralmente o único que dispõem; que ditam conteúdos e metodologias, levando muitas vezes à falta de autonomia na prática de ensino dos docentes. Fica muito nítido na argumentação das pesquisas, que o objetivo não é condenar os livros analisados, até porque frisam que analisaram livros aprovados pelo Plano Nacional do Livro Didático (PNLD); nem é o propósito apontar qual é o LD mais adequado. O discurso que emerge das obras é mais no sentido de apontar fragilidades, lacunas e defasagens presentes nos conteúdos dos livros para que estes sejam melhorados a cada avaliação do PNLD. Os Doc. 20 e 26 vêm preencher lacunas apontadas por Amaral (2006) quanto à carência de pesquisas sobre LD que abordem conceitos estruturantes da área e que problematizem o uso dos livros na prática dos professores. 
O interesse em investigar o LD tem suas raízes desde 1960, no contexto da ampliação de vagas da Educação Básica. Essa demanda teve dois desdobramentos: o aumento significativo de professores, muitos com formação deficiente em licenciatura de curta duração e sem a possibilidade de atualização, logo passaram a depender dos manuais escolares. E o segundo consistiu na presença de uma nova clientela de baixo poder aquisitivo, que passa a demandar do Governo uma política de distribuição gratuita de LD, iniciada em 1980 e mantida até o presente, convertendo o Estado no principal agente financiador de LD para a Educação Básica (BRAGA, 2003).

Desde então, os LD são alvos de investigações devido ao uso extremamente diverso em sala de aula, e por seu relevante papel nas práticas escolares ao agirem como guias curriculares influenciados por movimentos educacionais, científicos e cotidianos. Eles acabam definindo o que e como ensinar, impõem uma rotina de trabalho em sala de aula, que se distribui no tempo escolar, e ainda influenciam na formação docente. Ao mesmo tempo, os LD também são ressignificados e recontextualizados durante as atividades escolares (GOMES, 2008; BRAGA, 2003).

Ferreira e Selles (2003) apontam que a produção acadêmica sobre LD, em geral, desconsidera a complexidade dos processos envolvidos na seleção e organização desses materiais de ensino. Reconhecemos esses aspectos discutidos de forma mais crítica em quatro teses (Doc. 4, 5, 11 e 26), as quais problematizam, juntamente com o objeto de pesquisa, as instâncias de produção do LD: a editoração, a distribuição, a avaliação pelo PNLD, as exigências educacionais de diretrizes curriculares, as recomendações das comunidades de pesquisadores em ensino, as necessidades dos alunos e professores da Educação Básica, as relações mercadológicas entre autores, Estado e editoras, dentre outros aspectos, que condicionam sua produção e circulação, e que tornam complexa e tensa a relação dos diferentes sujeitos da educação e o uso e conteúdo do LD.

O segundo conjunto de obras que mais aglutinou pesquisas $(27,6 \%)$ foi 'Tecnologias da Informação e Comunicação' (TIC), que tiveram como objetos de investigação: os ambientes virtuais de aprendizagem (Doc. 9, 18, 21), softwares (Doc. 3), recursos da internet (Doc. 24, 29) e uso de computadores como recurso para o ensino-aprendizagem (Doc. 1, 14). Compreendemos que esse destaque sobre as TIC se deve principalmente porque estamos vivenciando uma "era digital", na qual o acesso aos recursos de informática e à internet já faz parte da realidade da maioria dos brasileiros e, devido ao papel cada vez maior que eles têm desempenhado nos processos educacionais nas últimas décadas.

Segundo Santa-Rosa (2010 - Doc. 18), a Tecnologia Educacional iniciou nos Estados Unidos da América na época da II Guerra Mundial, para o treinamento mais eficaz de militares. No Brasil, foi adotada como meio para massificação e formação profissional para o trabalho, isto é, com objetivo de capacitar mão de obra barata para a indústria e para a implantação de uma política tecnicista imposta pelo regime militar.

Nesse contexto, a educação não presencial tem utilizado as TIC para promover o aprendizado aos estudantes das mais diversas áreas do conhecimento e níveis de ensino. $\mathrm{O}$ crescimento de cursos a distância tem ocorrido devido à flexibilização do tempo, a quebra de barreiras espaciais e a emissão e o recebimento instantâneo de materiais digitalizados e hipermidiáticos. Apesar de suas vantagens, a tecnofobia e o analfabetismo digital de professores e alunos e 
a visão mercadológica adotada por algumas instituições têm despertado reações negativas quanto ao seu uso, e feito com que escolas e universidades não estejam adotando, ou estejam explorando pouco todo o potencial oferecido pelas TIC (SANTA-ROSA, 2010 - Doc. 18; FERREIRA, 2011 - Doc. 21).

O terceiro bloco de teses que aborda a problemática 'Recursos Lúdicos', aglutinou quatro teses $(13,8 \%)$ que investigaram o emprego de jogos e histórias em quadrinhos como recursos didáticos (Doc. 15, 16, 23 e 27). O quarto bloco de teses sobre RD é constituído por duas pesquisas (6,9\%) que abordam os 'Recursos Audiovisuais e Imagéticos' que tiveram como questão central as imagens no processo de produção de conhecimentos e os vídeos na formação inicial (Doc. 6 e 28). O último bloco de pesquisas denominado 'Outros Recursos', estão incluídas seis pesquisas $(17,2 \%)$ que analisam a utilização de revistas, artigos, textos diversos, mapas conceituais, dentre outros recursos (Doc. 7, 9, 10, 12, 17, 19).

\section{ESTRUTURA TEÓRICA DAS TESES SOBRE RECURSOS DIDÁTICOS EM ENSINO DE BIOLOGIA}

Apresentamos acima, em linhas gerais, o que os autores das teses tinham como temas e objetivos de pesquisa. Nesta seção nos dedicamos a análise hermenêutica do arcabouço teórico das 24 obras que estavam disponíveis na íntegra nas plataformas (do total de 29 teses), identificando filiações teóricas assumidas nelas, elencando as teorias e os conceitos estruturantes que refletem as perspectivas teóricas que as fundamentaram.

$\mathrm{Na}$ análise das obras verificamos que a maioria (18 teses das 24 analisadas) assume explicitamente qual o referencial teórico adotado na análise e discussão do objeto investigado. Há obras que anunciam seu referencial teórico e o apresentam em linhas gerais logo na introdução do trabalho; outras obras, além disso, apresentam em uma seção à parte a teoria em si, explicitando seus principais autores, conceitos fundamentais, contextos de origem e abordagens. Poucas obras (Doc. 5, 7, 12, 26) mencionam no resumo do trabalho qual foi o aporte teórico adotado.

Dessas 18 teses que especificam o referencial teórico adotado, identificamos que a principal corrente teórica assumida nas pesquisas sobre RD no EB está vinculada às perspectivas Construtivistas (10 teses), seguida pelas Perspectivas Críticas, (4 teses) e a Transposição Didática de Chevallard (4 teses), e ainda pelas Teorias da Linguagem (3 teses). É importante destacar que três teses (Doc. 11, 12, 25) assumem duas perspectivas teóricas, além disso, embora o Doc. 7 não estivesse disponível, o autor menciona no resumo do trabalho qual a fundamentação teórica de sua pesquisa, por isso o número de documentos na Tabela 4, abaixo, excede o número de 24 obras analisadas. 
Tabela 4. Perspectivas teóricas das 24 teses analisadas sobre Recursos Didáticos em Ensino de Biologia (1972-2014).

\begin{tabular}{l|l}
\hline \multicolumn{1}{c|}{ Perspectiva teórica } & \multicolumn{1}{c}{ Documento } \\
\hline $\begin{array}{l}\text { Construtivismos (Construtivismo Contextual, Modelos } \\
\text { Mentais, Psicologia Cognitivista, Psicologia Piagetiana) }\end{array}$ & $\begin{array}{l}\text { Doc. 8, 15, 18, 19, 21, 23, 24, } \\
25,27,29\end{array}$ \\
\hline Não assume & Doc. 2, 3; 4, 6, 13, 20, 28 \\
\hline Transposição Didática (Chevallard) & Doc. 7, 11, 22, 25 \\
\hline Perspectivas Críticas & Doc. 11, 12, 14, 26 \\
\hline Teorias da Linguagem & Doc. 5, 12, 17 \\
\hline
\end{tabular}

Há seis obras que não assumem explicitamente nenhuma filiação teórica, no entanto, possuem fundamentação teórica, porém, são referenciais sobre temas específicos que ajudam a discutir seus objetos de investigação, como referenciais sobre ecologia (Doc. 2), informática educacional (Doc. 13 e 3), imagens (Doc. 4 e 6), vídeos (Doc. 28) e teorias sobre a origem da vida (Doc. 20).

$\mathrm{Na}$ leitura e análise localizamos alguns conceitos estruturantes que foram utilizadas com frequência nas discussões ao longo das teses. Eles foram sendo identificados ao longo da leitura das obras e selecionados à medida que verificávamos a frequência tanto dentro da própria obra, isto é, os conceitos estruturantes apareciam e se repetiam em diferentes partes dos textos, quanto foram recorrentes em diferentes obras. Agrupamos os conceitos de acordo com as perspectivas teóricas as quais frequentemente estão vinculadas e em quais teses elas foram recorrentes (Tabela 5). Vale ressaltar que o número de Documentos na tabela abaixo é superior ao número de teses analisadas, pois os documentos estão registrados mais de uma vez de acordo com os conceitos estruturantes que apresentam, porquanto uma mesma tese utiliza um ou mais conceitos estruturantes da perspectiva teórica assumida e, em muitos casos, de outras abordagens teóricas também. 
Tabela 5. Perspectivas teóricas e conceitos estruturantes abordados nas 24 teses sobre Recursos Didáticos em Ensino de Biologia no período de 1972 a 2014.

\begin{tabular}{|c|c|c|}
\hline Perspectiva teórica & Conceitos estruturantes & Documento \\
\hline \multirow{2}{*}{ Construtivismos } & Conhecimentos prévios & $\begin{array}{c}5,6,8,12,17,18,19,22 \\
23,24,25,27,29\end{array}$ \\
\hline & Aprendizagem significativa & $\begin{array}{c}6,13,15,17,18,22,23,24 \\
27,29\end{array}$ \\
\hline \multirow{4}{*}{ Teorias críticas } & Mediação & $6,12,14,21,26$ \\
\hline & Problematização & $6 ; 12,14,24,26$ \\
\hline & Dialogicidade & $12,14,23,26$ \\
\hline & $\begin{array}{l}\text { CTS, alfabetização científica, } \\
\text { letramento científico }\end{array}$ & $12,17,24,26,27,29$ \\
\hline Transposição Didática & $\begin{array}{l}\text { Transposição didática, } \\
\text { transferência didática }\end{array}$ & $6,7,11,17,22,25$ \\
\hline \multirow{2}{*}{ Teorias da linguagem } & Gêneros de discurso de Bakhtin & 5,12 \\
\hline & Semiótica de Peirce & 17 \\
\hline
\end{tabular}

É importante perceber através da comparação entre as Tabelas 4 e 5 que, embora uma obra assuma determinada perspectiva teórica, nem sempre ela utiliza os conceitos próprios daquela teoria, ou então cita com frequência conceitos que são típicos de outra perspectiva teórica. Por essa razão as duas tabelas quando comparadas apresentam aparente diferença. Como é o caso do Doc. 21 que assume a abordagem Construtivista, mas utiliza conceitos de outras perspectivas; ou o caso da Teoria da Transposição Didática que é assumida por quatro obras, mas seus conceitos são utilizados com frequência por mais duas outras obras.

Grande parte (44\%) das pesquisas sobre RD que analisamos estão vinculadas às perspectivas Construtivistas (Doc. $8,15,18,19,21,23,24,25,27,29)$, e até mesmo obras que não assumem utilizá-la como referencial fazem uso recorrente de conceitos que lhe são estruturantes (Doc. 5, 6, 12, 13, 17). Em geral, as obras que justificaram a escolha por referenciais construtivistas estavam apostando na utilização de algum recurso alternativo de ensino, tendo como objetivos a aplicação e avaliação desses recursos, como, por exemplo, a utilização de recursos lúdicos, como jogo e histórias em quadrinhos (Doc. 15; 23, 25), de recursos tecnológicos (Doc. 18, 21, 24, 29), ou mesmo produzindo um novo material de ensino (Doc. 19). Seus autores se filiam ao construtivismo com o discurso de que por esse viés teórico seria possível suplantar a ineficácia do ensino tradicional e proporcionar aos estudantes, através do recurso que aplicam, uma aprendizagem mais significativa. 
Não há dúvidas, e isso é discutido e demonstrado por diversos autores da área (CACHAPUZ, 1999; CACHAPUZ et al., 2001; 2004; KRASILCHIK, 1987; 2000; LEMGRUBER, 1999; SLONGO, 2004) de que as perspectivas Construtivistas se configuraram como a principal corrente teórica na área de EC e, como percebemos nas tabelas acima, mais especificamente também no EB.

A predominância de um referencial teórico numa área de investigação pode ser perigosa por um lado, pois é possível que se torne em modismo teórico, o que facilita produções pouco consistentes e frágeis pelos reducionismos e apropriações acríticas; ao mesmo tempo que, por outro, garante fácil aceitação/ aprovação/divulgação pela/na comunidade de pesquisadores que compartilham daquele referencial. Como por exemplo, em um dos trabalhos o autor justifica a adoção da abordagem construtivista devido ao alto prestígio e aceitação que essa corrente possui na área: "a estratégia pedagógica mais conceituada hoje é o construtivismo, que considera a aprendizagem um processo pessoal, ou grupal, visando construir novos conhecimentos" (Doc. 21, p. 4).

Foi essa fragilidade teórica que percebemos na análise de algumas obras (Doc. 8, 21). Embora essas pesquisas tenham assumido sua filiação teórica junto ao Construtivismo, elas não situam a teoria ou o fazem de maneira muito superficial, em outros termos, elas não discorrem sobre a teoria ou abordagem que estão adotando, apresentando seus principais autores e, o que é mais alarmante, nem vinculam e/ou justificam a utilização de tal teoria para analisar seu objeto de investigação.

Concordamos com Cachapuz et al. (2001) quando estes chamam atenção sobre a necessidade de superação do reducionismo conceitual que marcou, e como vimos, ainda marca, algumas investigações construtivistas. Outra consequência do modismo teórico do construtivismo foi que alguns de seus conceitos próprios viraram senso comum pedagógico, ou seja, os conceitos são utilizados sem qualquer rigor, de forma naturalizada e corriqueira, a exemplo dos termos: conhecimentos prévios, concepções alternativas e aprendizagem significativa (CACHAPUZ et al., 2004).

Teixeira (2008) identificou as seguintes abordagens no chamado Construtivismo: Construtivismo Piagetiano; Teoria da Aprendizagem Significativa; Sociointeracionismo; Construtivismo Contextual; Cognitivismo; Modelos Mentais. Essa diversidade de abordagens também foi identificada nos trabalhos que analisamos: Construtivismo Contextual (Doc. 25), Modelos Mentais (Doc. 19), Psicologia Cognitivista Piagetiana (Doc. 24). Por isso a importância que se esclareça qual a perspectiva que se defende, uma vez que o construtivismo é um conceito multifacetado e alberga várias correntes que nem sempre são coerentes.

Os conceitos associados aos Construtivismos mais recorrentes nas obras foram a 'aprendizagem significativa' (10 teses) e os 'conhecimentos prévios' (13 teses). Dentro da perspectiva construtivista os conceitos aprendizagem significativa e conhecimentos prévios estão intimamente relacionados. No entanto, como mencionado acima, localizamos esses conceitos, alguns de forma isolada, também em obras que não se filiam a este referencial teórico, usando-os como senso comum pedagógico.

Ao longo das últimas décadas, as abordagens construtivistas foram se diversificando e adquirindo novas abordagens, por exemplo, nas obras que analisamos observamos um enfoque menos cognitivista e mais crítico da produção e apropriação do conhecimento pelos sujeitos, levando em conta o contexto educacional. Apesar da diversificação, a abordagem Construtivista também foi 
alvo de duras críticas que ocasionaram, a partir dos anos de 1990, uma tendência ao declínio, embora continuem sendo largamente as mais utilizadas na área de EC, como apontam os resultados desta pesquisa.

De acordo com Cachapuz (1999), o declínio desse movimento se deu em razão de suas várias limitações, como a valorização de uma imagem de ciência de sentido internalista; em privilegiar os conteúdos enquanto fins e não enquanto meios instrucionais para, a partir deles, se atingirem metas educacionais mais relevantes; os resultados de investigações não permitiram fundamentar a superioridade de tais perspectivas de ensino. Foi nesse contexto, diante das críticas e da intensa pesquisa levada a quase exaustão das abordagens Construtivistas, que segundo Lemgruber (1999), outros referenciais começam a ascender, como a adoção de abordagens freireanas ou aqueles advindos das discussões sobre CTS.

A segunda perspectiva teórica que mais aglutinou trabalhos são as chamadas perspectivas Críticas (4 teses), representadas por aqueles trabalhos que assumiram explicitamente o referencial adotado, como a Teoria HistóricoCultural de Vygotsky (Doc. 14, 26), a perspectiva Progressista de Freire (Doc. 12) e as Teorias Críticas do Currículo (Doc. 11). Além desses trabalhos, outras sete teses (Doc. 6, 17, 21, 23 24, 27, 29) utilizam frequentemente conceitos estruturantes das perspectivas Críticas e das abordagens Ciência-Tecnologia-Sociedade, que também poderiam ser incluídas no mesmo grupo de Críticas. As obras que utilizaram abordagens críticas buscavam problematizar temas cotidianos que envolvem ciência, tecnologia e sociedade, como a geração de energia, uso de medicamentos e o bioma cerrado (Doc. 17, 27, 29); outras obras problematizaram diferentes recursos de divulgação científica (Doc. 12, 14, 24, 26), e outras problematizavam os conhecimentos mediados por diferentes recursos didático, como as imagens (Doc. 6), os livros didáticos (Doc. 11), as TIC (Doc. 21) e jogos (Doc. 23).

Caracterizamos as perspectivas Histórico-Cultural, Progressista, as Teorias Críticas do Currículo e as abordagens CTS sob o rótulo de Críticas, porque elas possuem enfoques convergentes, implicadas no interesse pela emancipação e pela reflexão. A crítica se caracteriza pela desconfiança em relação ao que acontece na linguagem e por uma proposta de saída da alienação em direção a uma maior emancipação das pessoas (GHEDIN, 2004). Segundo Ricoeur (1990), há um mundo manifestado diante da realidade e a crítica é a possibilidade de compreensão de outras dimensões da realidade dada e das ilusões do sujeito, num conceito de compreensão de si. Mesmo que não haja reflexão total, o exercício da crítica possibilita ao sujeito ser consciente de estar sempre aberto e exposto aos efeitos ou às influências históricas.

Dois conceitos são centrais na perspectiva Progressista de Freire: a problematização e a dialogicidade. Embora apenas uma obra sobre RD em EB das que analisamos assuma a perspectiva Progressista, identificamos esses conceitos recorrentes em outras obras: a problematização, em cinco obras (Doc. 6; 12, 14, 24, 26), e a dialogicidade, em quatro obras (Doc. 12, 14, 23, 26). Duas obras (Doc. 12 e 24) mencionam utilizar como parte das etapas de pesquisa um método de ensino próprio da perspectiva freireana: os Três Momentos Pedagógicos ou 3MP, definidos pela (i) problematização inicial, (ii) organização do conhecimento e (iii) aplicação do conhecimento (NASCIMENTO, 2008 - Doc. 12). 
O referencial de Paulo Freire tem sido associado muito frequentemente com as abordagens CTS. Essa estreita relação ocorre principalmente porque elas utilizam alguns conceitos e sistemáticas que são comuns a ambas abordagens: palavras geradoras, investigação temática, educação política, participação pública, educação problematizadora e a não-neutralidade da concepção de ciência (ZAUITH; HAYASHI, 2013). A obra de Nascimento (2008, Doc. 12) faz essa articulação por acreditar que ambas promovem um ensino com validade cultural, que privilegia abordagens e métodos de ensino que contemplam os mais diversos tipos de acontecimentos da esfera social, isto é, que ultrapassa a aprendizagem mecânica de conceitos e de teorias relacionadas com conteúdos canônicos.

Apesar da aparente semelhança e tentativa de articulação entre as duas abordagens, o estudo de Auler et al. (2009) evidenciou que há dissonância entre elas nas pesquisas CTS que utilizam temas. Isto porque, em Freire, o tema surge a partir da efetiva participação da comunidade escolar, eles são constituídos de manifestações locais, de contradições presentes na dinâmica social; além disso, as disciplinas envolvidas não ficam restritas a uma área de conhecimento. Já nas pesquisas com enfoque CTS, a escolha dos temas é hegemonicamente definida pelo professor, os temas são abrangentes, não vinculados a contextos específicos, e as disciplinas envolvidas ficam restritas às disciplinas de Biologia, Física, Química, Geologia e Matemática.

Outra perspectiva teórica com abordagem Crítica adotada em duas obras de EB que analisamos é a Teoria Histórico-Cultural (Doc.14, 26). Essa abordagem teórica é a denominação usualmente dada à corrente psicológica de Vygotsky que explica o desenvolvimento da mente humana com base nos princípios do materialismo dialético. Ao realçar a atividade sócio-histórica e coletiva dos indivíduos na formação das funções mentais superiores, essa concepção afirma o caráter de mediação cultural do processo do conhecimento e, ao mesmo tempo, a dimensão individual da aprendizagem pela qual o indivíduo se apropria ativamente da experiência sociocultural (LIBÂNEO; FREITAS, 2006). Na concepção histórico-cultural, a mediação é um conceito-chave, e sua utilização como conceito estruturante foi identificada em cinco obras (Doc. 6, 12, 14, 21, 26).

Foram identificadas três obras sobre RD em EB que utilizaram como referencial de análise as Teorias da Linguagem (Doc. 5, 12, 17), que foram o Gênero de Discurso de Mikhail Bakhtin e a Semiótica de Charles Sanders Peirce. Essas pesquisas tinham como objeto de análise a própria linguagem, na forma de texto no livro didático (Doc. 5), textos de divulgação científica (Doc. 12), ambas a partir dos gêneros de discurso de Bakhtin e, também, para a construção de um diagrama sobre os estudos ecológicos a partir da semiótica peirceana (Doc. 17). Agrupamos essas duas teorias num mesmo grupo que denominamos "Teorias da Linguagem" devido a linguagem ser a questão central analisada por seus teóricos.

Para Bakhtin, os gêneros de discurso pertencem a diversos tipos de discursos associados a vários setores da atividade social. Nessa perspectiva, Nascimento (2008 - Doc. 12) concluiu que o texto de Biologia do livro didático de Ciências constituiria um gênero de discurso, pois ele estaria inserido no interior do tipo de discurso que se denomina de "científico escolar". Este, por sua vez, faz parte de um conjunto mais amplo de discurso - o "pedagógico" - que figuraria dentro de outros discursos, de diferentes espaços de aprendizagem do indivíduo. Brando 
(2010 - Doc. 17) justificou a escolha do referencial peirceano por considerar que ele permite investigar os processos sígnicos na natureza e contribui com diagramas analíticos que fornecem possibilidades de estudar as relações que se estabelecem, por exemplo, nos fenômenos biológicos.

A Teoria da Transposição didática, desenvolvida por Chevallard, fundamentou teoricamente quatro obras (Doc. 7, 11, 22, 25) e foi citada como conceito estruturante em outras duas (Doc. 6, 17). As pesquisas que a utilizaram como referencial tinham como objetivo analisar o processo de produção de materiais pedagógicos por professores da Educação Básica (Doc. 7); o estudo sócio-histórico dos conteúdos de ensino de ecologia presente nos LD (Doc. 11); o desenvolvimento e avaliação de livro técnico-didático sobre biomonitoramento (Doc. 22); analisar aproximações e distanciamentos dos conteúdos de genética nos LD com a bibliografia de referência (Doc. 25).

A transposição didática consiste em linhas gerais, no trabalho de transformar um objeto de saber em um objeto de ensino, devido ao funcionamento do saber educacional (saber ensinado) ser diferente do funcionamento acadêmico (saber sábio), por isso estes passam por modificações que, mediadas por um conjunto de fatores de ordem político-social, os transformam em objeto a ser ensinado (SELLES; FERREIRA, 2004).

Tendo como base a análise realizada sobre as perspectivas teóricas das teses, compreendemos que a produção acadêmica em EB encontra-se no terceiro período histórico-epistemológico, conforme descrito por Slongo (2004), caracterizado pela intensa circulação da produção e consolidação desse campo de investigação. Pois consideramos que as obras apresentaram nas últimas duas décadas, discursos baseados em reflexões mais aprofundadas, incluindo temas como a alfabetização científica e uma discussão mais crítica e densa sobre currículo. Essa abordagem tem projetado epistemologicamente a subárea de EB, no Brasil, numa perspectiva cada vez mais crítica, especialmente, pelo comparecimento das teorias críticas da educação e do conhecimento.

A partir desse entendimento, acreditamos que esteve ocorrendo, nas últimas décadas, especificamente a partir de meados da década de 1990, um processo de construção de um compêndio teórico de referência para a subárea de EB. Consideramos que já é possível argumentarmos que a subárea de EB tem se estruturado em torno de um arcabouço teórico próprio, que leva em conta tanto a realidade educacional brasileira, quanto as especificidades do ensino dos conteúdos biológicos e científicos, e não mais fundamentam-se apenas em referências gerais da Educação, da Psicologia ou da Filosofia.

Essa não foi uma construção que ocorreu somente nas últimas décadas, mas ocorreu como resultado da constituição e amadurecimento da área de Ensino de Ciências como um todo, num esforço coletivo de pesquisadores em mais de 40 anos de investigações na área.

\section{CONSIDERAÇÕES}

Nosso ponto de partida para a formulação da questão norteadora desta pesquisa foi a problematização da constituição epistemológica da área de EB e suas 
implicações na evolução do campo. A questão de pesquisa se desdobrou no objetivo de analisar a estrutura teórica que tem fundamentado a produção doutoral brasileira sobre RD em EB no período de 1972 a 2014. A fim de compreender de que forma a subárea de EB tem se constituído em torno de referenciais teóricos particulares, devido às condições históricas de produção e disseminação das pesquisas.

Apesar desse claro avanço, de uma abordagem mais crítica dos objetos educacionais, algumas pesquisas carecem de um aprofundamento teórico maior, percebida em cerca de metade das obras analisadas, dentro dos limites teóricos que assumem. Consideramos que a carência de aprofundamento teórico ocorre mais naqueles trabalhos que são produzidos no interior de programas de pós-graduação de áreas específicas das ciências naturais, como em programas de Biociências, Biologia Geral e Física, do que as pesquisas desenvolvidas em programas específicos de Ensino de Ciências ou de Faculdades de Educação.

Cremos que não se trata de uma dificuldade relacionada somente a procedência da área do conhecimento. Infelizmente, de acordo com Gatti (2001), esse é um problema encontrado também na produção das pesquisas na área educacional, e igualmente um fato que ocorre em nível internacional. Aliado a isso, temos o problema do produtivismo acadêmico, isto é, a exigência de maior produção em menor tempo pela CAPES, universidades e mercado de trabalho. O que acarreta na falha de uma sólida formação de pesquisadores e na ausência de robustez dos textos, no que tange ao aprofundamento teórico; a proposição de hipóteses mais consistentes; de colocação de questões de pesquisa mais densas, que somados podem contribuir para o desenvolvimento mais sólido da pesquisa em nosso país.

A hermenêutica que realizamos sobre as obras, juntamente com análise de outras referências, mediou nossa compreensão sobre a configuração históricoepistemológica da área, possibilitando-nos defender a tese de que as pesquisas sobre RD em EB no Brasil estão fundamentadas em um compêndio teórico particular, que se vincula epistemologicamente às perspectivas cognitivistas, educacionais e críticas do conhecimento. É importante frisar que defendemos essa tese baseados em um recorte específico, isto é, em relação às teses sobre RD que, por isso mesmo, nos impõem limites. Mesmo dentro dos limites do recorte que fizemos, o compêndio teórico que identificamos não é fixo, pois o contexto social, político, educacional no qual ele é produzido é dinâmico, portanto, as teorias que interpretamos ganham outros sentidos através da recontextualização que sofrem e ao sabor do devir histórico.

Não temos a pretensão de generalizar nossas interpretações, contidas dentro dos contornos das próprias teorias que aqui analisamos, para toda a subárea de Ensino de Biologia. Entendemos que a compreensão das características histórico-epistemológicas dos outros focos temáticos da produção em EB, para análise na íntegra de toda a produção, a fim de identificar os aportes teóricos das mesmas, seria possível somente através de um esforço analítico coletivo que se desdobrasse em um programa de pesquisa, devido ao grande volume de trabalhos que cada vez mais é crescente.

A tarefa que realizamos, foi um esforço para, junto com outras obras, produzir uma memória, através do discurso que inscrevemos nesta obra, para a subárea em EB. Acreditamos que fizemos isso ao resgatar as teses em RD produzidas desde a fundação da área e interpretar o modo pelo qual histórica- 
epistemologicamente elas projetam um modo de pensar, de ver, de compreender e explicar o Ensino de Biologia.-Por quanto as obras que analisamos por si mesmas já atualizam a memória do EB, sendo um vínculo que, ao mesmo tempo, relaciona o passado e o futuro no presente a partir de uma história que vai se construindo por esses trabalhos nessa área de pesquisa e que projetam essa ciência para uma nova compreensão, no avanço do desenvolvimento das perspectivas do campo.

Segundo Ricoeur (1969), toda tradição vive no tempo e pelo tempo da interpretação, pois tradição é a que transmite, e a interpretação a que renova e marca nosso enraizamento a uma tradição, à nossa pertença ao mundo. Por isso a tradição, fica morta se não for vivificada e renovada pela interpretação da riqueza e potência do símbolo. Aí reside a eficácia e a necessidade de trabalhos de estado do conhecimento como este que empreendemos, pois, a grande maioria das obras de discurso em formato de teses e dissertações acabam caindo no esquecimento após serem publicadas e arquivadas nas bibliotecas dos respectivos programas de pós-graduação.

Ao serem realizados trabalhos como este é possível mantermos viva a memória da área de pesquisa em Ensino de Biologia, porquanto a interpretação ocorre sempre em novas condições existenciais que exigem uma descrição e uma explicação que mediam o compreender e renovam a tradição. Nesse sentido, nossa intenção foi contribuir no desenvolvimento histórico-epistemológico da mesma, a partir da mediação para a fértil reflexão sobre lacunas, desgastes, tendências, sentidos, teorias, proposições que podem projetar novos horizontes de compreensão em futuras pesquisas da área.

\section{REFERÊNCIAS}

ALMEIDA, M. J. P. M. Fundamentos da pesquisa no ensino de ciências e física. In: Encontro de Pesquisa em Ensino de Física. Resumos... Sociedade Brasileira de Física, Universidade Federal de Santa Catarina, Florianópolis, 26 a 28 de maio de 1994.

AMARAL, I. A. Os fundamentos do ensino de Ciências e o livro didático. In: FRACALANZA, H; MEGID NETO, J. (org.). O livro didático de ciências no Brasil. Campinas: Komedi, 2006.

AULER, D; DALMOLIN, A. M. T; FENALTI, V. S. Abordagem Temática: natureza dos temas em Freire e no enfoque CTS. Alexandria Revista de Educação em Ciência e Tecnologia, Florianópolis, v. 2, n.1, p. 67-84. 2009.

BRAGA, S. A. M. O texto de Biologia do livro didático de Ciências. Tese (Doutorado em Educação). Faculdade de Educação. Universidade Federal de Minas Gerais. 2003.

CACHAPUZ, A. Epistemologia e ensino das ciências no pós mudança conceptual: análise de um percurso de pesquisa. In: Atas do II Encontro Nacional de Pesquisa em Educação em Ciências. Valinhos: ABRAPEC. 1999.

CACHAPUZ, A, A.; PRAIA, J.; GIL-PEREZ, D.; CARRASCOSA, J. e MARTÍNEZ-TERRADES, F. A emergência da didáctica das ciências como campo específico de conhecimento. Revista Portuguesa de Educação, Braga, 2001, v. 14, n. 1, p. 155-195.

CACHAPUZ, A, A; PRAIA, J; JORGE, M. Da educação em ciência às orientações para o ensino das ciências: um repensar epistemológico. Ciência \& Educação, Bauru, v. 10, n. 3, p. 363-381, 2004. 
CAPES. Portaria $\mathbf{N}^{\mathbf{0}} \mathbf{0 8 0}$, de 16 de dezembro de 1998. Dispõe sobre o reconhecimento dos mestrados profissionais e dá outras providências.

CUNHA, L. A. Pós-Graduação em educação: no ponto de inflexão? Cadernos de Pesquisa. São Paulo, n. 77, p. 63-80, maio 1991.

DELIZOICOV, D. Pesquisa em ensino de Ciências como Ciências Sociais Aplicadas. Caderno Brasileiro de Ensino de Física, Florianópolis, v. 21, n.2, p.145-175, ago. 2004.

FERNANDES, R. C. A; MEGID-NETO, J. Pesquisas sobre o estado da arte em Educação em Ciências: uma revisão em periódicos científicos brasileiros. In: Atas do VI Encontro Nacional de Pesquisa em Educação em Ciências. Florianópolis: ABRAPEC. 2007.

FERREIRA, M. S.; SELLES, S. E. A produção acadêmica brasileira sobre livros didáticos em Ciências: uma análise em periódicos nacionais. In: Atas do IV Encontro Nacional de Pesquisa em Educação em Ciências, Bauru/São Paulo. 2003.

FREITAS, L. M. Recursos Didáticos em Ensino de Biologia: analise histórico-epistemológica da produção doutoral brasileira (1972-2014). Tese (Doutorado em Educação em Ciências). Universidade Federal de Mato Grosso. Cuiabá. 2016.

GHEDIN, E. Hermenêutica e pesquisa em educação: caminhos da investigação interpretativa. In: Anais do Seminário Internacional de Pesquisa e Estudos Qualitativos. Bauru: EDUSC, 2004. v. Único.

GHEDIN, E.; FRANCO, M. A. S. Questões de método na construção da pesquisa em educação. São Paulo: Cortez. 2011.

GOMES, M. M. P. L. Conhecimentos ecológicos em livros didáticos de Ciências: aspectos sócio-históricos de sua constituição. Tese. (Doutorado em Educação). Universidade Federal Fluminense. 2008.

GRECA, I. M.; COSTA, S. S. C.; MOREIRA, M. A. Análise descritiva e crítica dos trabalhos de pesquisa submetidos ao III ENPEC. Revista Brasileira de Pesquisa em Educação em Ciências, Belo Horizonte, v. 2, n.1: p.73-82, 2002.

KRASILCHIK, M. O professor e o currículo de Ciências. São Paulo: EPU/EDUSP, 1987.

KRASILCHIK, M. Reformas e Realidade: o caso do ensino de Ciências. São Paulo em Perspectiva, São Paulo, v. 14, n. 1, p. 85-93, 2000.

LEMGRUBER, M. S. A Educação em Ciências físicas e biológicas a partir das teses e dissertações (1981 a 1995): uma história de sua história. Tese (Doutorado em Educação) Faculdade de Educação. Universidade Federal do Rio de Janeiro. Rio de Janeiro, 1999.

LIBÂNEO, J. C.; FREITAS, R. A. M. M. Vygotsky, Leontiev, Davydov? Três aportes teóricos para a teoria histórico-cultural e suas contribuições para a didática. In: IV Congresso Brasileiro de História da Educação. Goiânia - GO: Editora Vieira/UCG, v. 1. p. 1-10, 2006.

LOPES, J. B.; PAIXÃO, F.; PRAIA, J.; GUERRA, C.; CACHAPUZ, A, F. Epistemologia da didática das ciências: um estudo sobre o estado da arte da investigação. Enseñanza de las Ciencias, Barcelona, n. extra, p.1-4. 2005.

MOREIRA, M. A. Pesquisa básica em educação em ciências: uma visão pessoal. Revista Chilena de Educación Científica, Santiago, v. 3, n. 1, p. 10-17. 2004. 
NARDI, R. A área de ensino de Ciências no Brasil: fatores que determinaram sua constituição e suas características segundo pesquisadores brasileiros. Tese (Livre docência). Universidade Estadual Paulista. Faculdade de Ciências, Bauru, 2005.

PIETROCOLA-OLIVEIRA, M. Onde estão nossos referenciais teóricos? In: IV Encontro de Pesquisa em Ensino de Física, VI, 1994, Resumos... Sociedade Brasileira de Física, Florianópolis, SC, p. 25-26.

RICOEUR, P. Interpretação e ideologias. Rio de Janeiro: Francisco Alves, 1990.

RICOEUR, P. O conflito das interpretações. Rio de Janeiro: Imago, 1969.

SÁ-SILVA, J. R; ALMEIDA, C. D; GUINDANI, J. F. Pesquisa documental: pistas teóricas e metodológicas. Revista Brasileira de História \& Ciências Sociais, São Leopoldo, ano 1, v. I, p 1-15. 2009.

SELLES, S. E; FERREIRA, M. S. Influências histórico-culturais nas representações sobre as estações do ano em livros didáticos de ciências. Ciência \& Educação, Bauru, v. 10, n. 1, p. 101-110, 2004.

SILVA, L. B. O. A interpretação hermenêutica em Paul Ricoeur: uma possível contribuição para a educação. Comunicações, Piracicaba, ano 18, n. 2, p. 19-36, 2011.

SLONGO, I. I. P. A produção acadêmica em Ensino de Biologia. Tese (Doutorado). Universidade Federal de Santa Catarina. Centro de Ciências da Educação, Florianópolis, 2004.

TEIXEIRA, P. M. M. Pesquisa em Ensino de Biologia no Brasil (1971-2004): um estudo baseado em dissertações e teses. Tese (Doutorado) - Universidade Estadual de Campinas. Faculdade de Educação, Campinas. 2008.

TEIXEIRA, P. M. M. A pesquisa em Ensino de Biologia no Brasil (1972-2011): um olhar sobre as teses de doutorado. In: Atas do X ENPEC- Encontro Nacional de Pesquisa em Educação em Ciências. Águas de Lindóia, SP. ABRAPEC. 2015.

VILLANI, A. Reflexões sobre o ensino de Física no Brasil: prática, conteúdos e pressupostos. Revista de Ensino de Física, São Paulo, v. 6, n. 2, 76-95, 1984.

ZAUITH, G; HAYASHI, M. C. P. I. A influência de Paulo Freire no ensino de ciências e na educação CTS: uma análise bibliométrica. Revista HISTEDBR On-line, Campinas, n. 49, p. 267-293, 2013.

\section{Submetido em 30/05/2017}

Aprovado em 16/04/2018

\section{Contato:}

Campus Universitário de Bragança

Avenida Leandro Ribeiro, s/n. Bairro Aldeia

CEP 68.600-000 - Bragança, Pará - Brasil 